06.1

\title{
Терагерцевое поглощение в композитных пленках на основе металлоорганического перовскита и смешанного эфира целлюлозы
}

\author{
() А.В. Андрианов, А.Н. Алешин \\ Физико-технический институт им. А.Ф. Иофффе РАН, Санкт-Петербург, Россия \\ E-mail: alex.andrianov@mail.ioffe.ru
}

Поступило в Редакцию 2 марта 2020 г.

В окончательной редакции 2 марта 2020 г.

Принято к публикации 3 марта 2020 г.

\begin{abstract}
Методом терагерцевой спектроскопии во временно́й области исследованы композиты на основе металлоорганического перовскита $\mathrm{CH}_{3} \mathrm{NH}_{3} \mathrm{PbI}_{3}$ и смешанного эфира целлюлозы. Показано, что введение смешанных сложных эфиров целлюлозы в прекурсор металлоорганического перовскита $\mathrm{CH}_{3} \mathrm{NH}_{3} \mathrm{PbI}_{3}$ существенно модифицирует параметры перовскита в терагерцевой области, а также улучшает стабильность таких композитных пленок. Установлено, что добавка смешанного эфира целлюлозы в пленку перовскита приводит к значительному ослаблению полос терагерцевого поглощения в области частот порядка 1 и $2 \mathrm{THz}$, обусловленных возбуждением низкочастотных колебательных мод в молекулах перовскита $\mathrm{CH}_{3} \mathrm{NH}_{3} \mathrm{PbI}_{3}$. Это может быть объяснено тем, что молекулы эфира целлюлозы, обволакивая молекулы перовскита, демпфируют низкочастотные колебания в них.
\end{abstract}

Ключевые слова: металлоорганические перовскиты, композиционные материалы, терагерцевая спектроскопия.

DOI: 10.21883/PJTF.2020.10.49434.18269

Материалы на основе металлоорганических перовскитов $\mathrm{CH}_{3} \mathrm{NH}_{3} M X_{3}(M=\mathrm{Pb}, \mathrm{Sn} ; X=\mathrm{Cl}, \mathrm{Br}, \mathrm{I})$ привлекают большое внимание в связи с их использованием в качестве активных слоев высокоэффективных солнечных элементов (СЭ) [1], которые в 2020 г. достигли значений эффективности преобразования солнечной энергии $25.2 \%$ [2], что сопоставимо со значениями для тонкопленочных СЭ на основе аморфного кремния. В то же время причины, обусловливающие высокую эффективность перовскитных СЭ, продолжают оставаться не до конца ясными. Поэтому в настоящее время металлоорганические перовскиты интенсивно исследуются с помощью самых различных методов [1]. В частности, выполнен целый ряд исследований металлоорганических перовскитов в терагерцевой $(\mathrm{THz})$ области спектра электромагнитных волн [3-5]. Наряду с этим вопросы стабильности перовскитных СЭ и светоизлучающих устройств, их чувствительности к влаге и кислороду являются основными проблемами, сдерживающими развитие этой технологии на данный момент [6]. Недавно было показано, что включение этилцеллюлозы в пленку перовскита $\mathrm{CH}_{3} \mathrm{NH}_{3} \mathrm{PbI}_{3}$ приводит к улучшению стабильности композита вследствие образования водородных связей с $\mathrm{CH}_{3} \mathrm{NH}_{3} \mathrm{PbI}_{3}$, которые стабилизируют кристаллическую структуру металлоорганического перовскита $[7,8]$. При этом свойства композитных пленок на основе перовскитов и смешанных эфиров целлюлозы в THz-области спектра до сих пор не были изучены.

В настоящей работе исследованы оптические свойства пленок композита перовскит $\mathrm{CH}_{3} \mathrm{NH}_{3} \mathrm{PbI}_{3}$-смешанный эфир целлюлозы в области спектра $0.2-2.9 \mathrm{THz}$. Установлено, что добавка эфира целлюлозы в пленку метал- лоорганического перовскита, способствующая предотвращению быстрой деградации перовскита и повышению стабильности его фотоэлектрических свойств в области межзонного поглощения [8], в то же время приводит к значительному ослаблению полос THz-поглощения в области частот порядка 1 и $2 \mathrm{THz}$, обусловленных возбуждением низкочастотных колебательных мод в молекулах перовскита $\mathrm{CH}_{3} \mathrm{NH}_{3} \mathrm{PbI}_{3}$.

Для приготовления образцов использовался порошок металлоорганического перовскита $\mathrm{CH}_{3} \mathrm{NH}_{3} \mathrm{PbI}_{3}$ (Xi'an Polymer Light Technology Corp.) с шириной запрещенной зоны $E_{g} \sim 2.3 \mathrm{eV}$ без дополнительной обработки. Смешанный сложный эфир целлюлозы (mixed cellulose ester, CE) был синтезирован по аналогии с предыдущими работами [9]. Для исследования был выбран смешанный эфир целлюлозы с ацетотриметилацетатом. На рис. $1, a, b$ показаны химическая структура смешанного эфира целлюлозы, а также структура металлоорганического перовскита $\mathrm{CH}_{3} \mathrm{NH}_{3} \mathrm{PbI}_{3}$, использованного в настоящей работе.

Смешанный сложный эфир целлюлозы, показанный на pис. 1, $a$, и порошок перовскита $\mathrm{CH}_{3} \mathrm{NH}_{3} \mathrm{PbI}_{3}$ (рис. 1, $b$ ) по отдельности растворялись в ДМФА (N, N-диметилформамиде), растворы смешивались вместе при различном относительном содержании компонентов с последующей обработкой на ультразвуковой мешалке Bandelin Sonopuls HD $2070(f \sim 20 \mathrm{kHz})$ в течение $10 \mathrm{~min}$. Полученные растворы наносились на кремниевые подложки (КДБ-10) методом полива, после чего образцы высушивались при $100^{\circ} \mathrm{C}$ в течение $10 \mathrm{~min}$ и выдерживались в вакуумных эксикаторах до проведения измерений. Толщина пленок, полученных методом поли- 

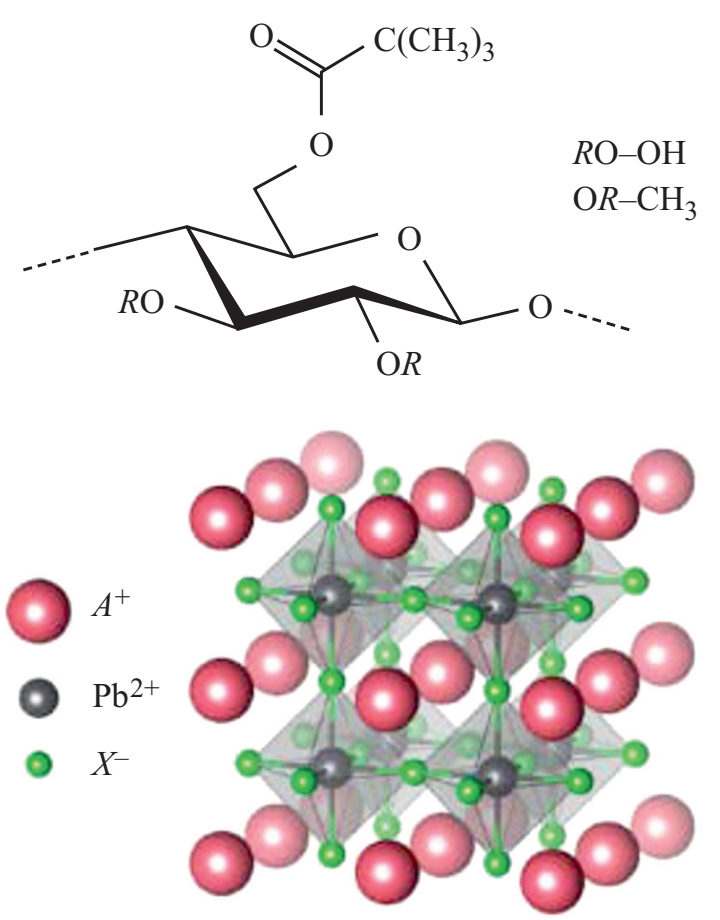

Рис. 1. Химическая структура смешанного эфира целлюлозы с ацетотриметилацетатом $(a)$ и металлоорганического перовскита $\mathrm{CH}_{3} \mathrm{NH}_{3} \mathrm{PbI}_{3}(b)$. $A-$ моновалентный катион $\mathrm{CH}_{3} \mathrm{NH}_{3}^{+}$, $X-$ ион галогена $\mathrm{I}^{-}$.

ва, согласно результатам атомно-силовой микроскопии, составила $\sim 2 \mu \mathrm{m}$. Были приготовлены и исследованы пленки композита перовскит $\mathrm{CH}_{3} \mathrm{NH}_{3} \mathrm{PbI}_{3}$ - смешанный эфир целлюлозы $\left(\mathrm{CH}_{3} \mathrm{NH}_{3} \mathrm{PbI}_{3}: \mathrm{CE}\right)$ с различным соотношением компонентов $\mathrm{CH}_{3} \mathrm{NH}_{3} \mathrm{PbI}_{3}$ и $\mathrm{CE}$ : от $100 \%$ перовскита до композитов с соотношением 0.95:0.05, $0.9: 0.1,0.7: 0.3$ и $0.4: 0.6$.

Исследование THz-характеристик тонких пленок композита $\mathrm{CH}_{3} \mathrm{NH}_{3} \mathrm{PbI}_{3}$ : $\mathrm{CE}$, нанесенных на кремниевые подложки, проводилось методом THz-спектроскопии во временно́й области (методика THz-TDS). Широкополосное $\mathrm{THz}-и з л у ч е н и е ~ г е н е р и р о в а л о с ь ~ п р и ~ н а к л о н н о м ~\left(45^{\circ}\right)$ падении на пластинку $n-\operatorname{InAs}(100)$ импульсов титан-сапфирового лазера длительностью $15 \mathrm{fs}$ с центральной длиной волны $800 \mathrm{~nm}$, следующих с частотой $80 \mathrm{MHz}$ и имеющих энергию в импульсе порядка $2.5 \mathrm{~nJ}$. Детектирование импульсного THz-излучения проводилось методом электрооптического стробирования THz-волновых форм в кристалле ZnTe ориентации (110) толщиной $1 \mathrm{~mm}$. Измерялось пропускание THz-излучения при его нормальном падении на образец $\mathrm{Si}$ с пленкой композита. B настоящей работе применялся дифференциальный вариант методики THz-TDS [10]. Измерения проводились в спектральной области $0.2-2.9 \mathrm{THz}$ со спектральным разрешением $0.1 \mathrm{THz}$ при комнатной температуре $(293 \mathrm{~K})$ на воздухе с влажностью порядка $56 \%$.

Комплексный коэффициент дифференциального пропускания $K_{d}(\omega)$ образца с тонкой пленкой исследуемого материала $\left(\left\|d \frac{\omega}{c} \tilde{n}\right\| \ll 1\right.$, где $d-$ толщина пленки, $\omega=2 \pi f-$ круговая частота, $\tilde{n}=n+i k-$ комплексный показатель преломления материала пленки, $c$ скорость света, $k$ - коэффициент экстинкции, прямо связанный с коэффициентом поглощения THz-мощности $\left.\alpha=2 \frac{\omega k}{c}\right)$ на толстой подложке с показателем преломления $n_{s}$ может быть представлен в следующей форме [10]:

$$
\begin{aligned}
K_{d}(\omega) & =\frac{E_{d i f}(\omega)}{E_{r e f}(\omega)}=i \frac{\omega d}{c\left(n_{s}+1\right)}\left(\tilde{n}^{2}-1\right) \\
& =i \frac{\omega d}{c\left(n_{s}+1\right)}\left(n^{2}-k^{2}-1+i 2 n k\right) .
\end{aligned}
$$

В уравнении (1) $E_{d i f}(\omega)-$ комплексная амплитуда дифференциального $\mathrm{THz}-$ сигнала для образца с исследуемой тонкой пленкой, которая есть $E_{\text {dif }}(\omega)=E_{\text {film }}(\omega)-E_{\text {ref }}(\omega)$. Величины $E_{\text {film }}(\omega)$ и $E_{r e f}(\omega)$ - соответственно комплексная амплитуда THz-сигнала, прошедшего через образец с исследуемой пленкой, и амплитуда сигнала, прошедшего через опорный образец (без композитной пленки). Комплексные амплитуды THz-сигналов могут быть получены с помощью фурье-преобразования соответствующих волно-

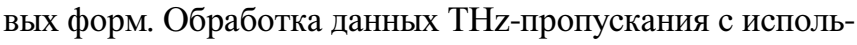
зованием уравнения (1) позволяет получить спектры THz-характеристик (коэффициента экстинкции и показателя преломления) для исследуемого материала [10].

На рис. 2 показаны характерные волновые формы $\mathrm{THz}$-сигнала, пропущенного через чистую подложку $\mathrm{Si}$, и дифференциального THz-сигнала для образца $\mathrm{Si} \mathrm{c}$ пленкой композита $\mathrm{CH}_{3} \mathrm{NH}_{3} \mathrm{PbI}_{3}: \mathrm{CE}$ с соотношением объемных долей 0.9 и 0.1 и толщиной $\sim 2 \mu \mathrm{m}$. Форма дифференциального сигнала отражает ослабление амплитуды и временно́е запаздывание THz-импульса, про-

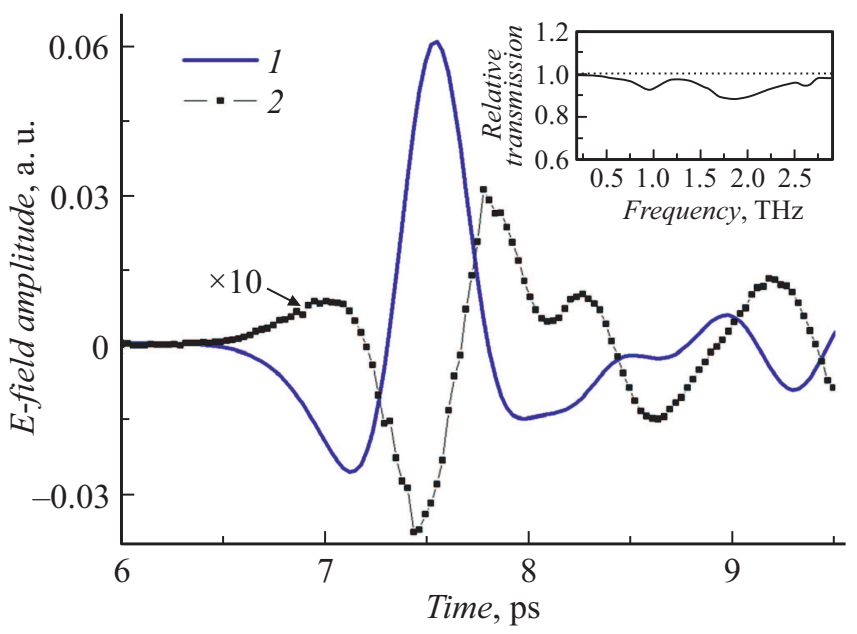

Рис. 2. Характерные волновые формы сигнала THz-излучения, прошедшего через опорный образец $c$-Si $(1)$, и дифференциального THz-сигнала (2) для образца $c$-Si c пленкой толщиной $2 \mu \mathrm{m}$ композита $\mathrm{CH}_{3} \mathrm{NH}_{3} \mathrm{PbI}_{3}: \mathrm{CE}$ с соотношением объемных долей $0.9: 0.1$. На вставке показан THz-спектр относительного пропускания $T_{f i l m+c-\mathrm{Si}} / T_{c-\mathrm{Si}}$ для образца с пленкой данного композита. 
шедшего через образец с пленкой исследуемого композита. На вставке приведен также THz-спектр относительного пропускания $T_{f i l m+c-\mathrm{Si}} / T_{c-\mathrm{Si}}$ (где $T_{f i l m+c-\mathrm{Si}}$ и $T_{c-\mathrm{Si}}-$ амплитудные коэффициенты THz-пропускания образца с пленкой композита и опорного образца соответственно) для образца с пленкой данного композита. В спектре видны полосы поглощения при частотах порядка 0.96 и $1.92 \mathrm{THz}$, ранее наблюдавшиеся в спектрах THz-поглощения объемного $\mathrm{CH}_{3} \mathrm{NH}_{3} \mathrm{PbI}_{3}[11,12]$, обусловленные возбуждением низкочастотных колебательных мод в молекулах перовскита.

На рис. 3, a приведены ТНz-спектры коэффициента экстинкции (характеристика поглощения) в области $0.2-2.9 \mathrm{THz}$ для композитов $\mathrm{CH}_{3} \mathrm{NH}_{3} \mathrm{PbI}_{3}: \mathrm{CE}$ с различной объемной долей целлюлозы. Можно видеть, что значения коэффициента экстинкции как на полосе поглощения в области $1 \mathrm{THz}$, так и на полосе в области $2 \mathrm{THz}$ в композите значительно уменьшаются с ростом содержания в нем смешанного эфира целлюлозы (см. также рис. 3, b,c). При этом резкий спад коэффициента экстинкции происходит при изменении содержания целлюлозы от 0 до 30\%. При дальнейшем росте содержания целлюлозы в композите особенности, связанные с возбуждением колебательных мод в области 1 и $2 \mathrm{THz}$, характерные для объемного перовскита $\mathrm{CH}_{3} \mathrm{NH}_{3} \mathrm{PbI}_{3}[11,12]$, уже не просматриваются в спектре коэффициента экстинкции. Данные, приведенные на рис. 3, $b, c$, показывают, что спад значений THz-коэффициента экстинкции в композите $\mathrm{CH}_{3} \mathrm{NH}_{3} \mathrm{PbI}_{3}: \mathrm{CE}$ с ростом объемной доли целлюлозы может быть аппроксимирован степенной функцией с показателем степени $-(0.8-1.1)$.

Наблюдаемые закономерности могут быть связаны с тем, что молекулы смешанного эфира целлюлозы, обволакивая молекулы перовскита, демпфируют низкочастотные колебания в них. При этом эфир целлюлозы предохраняет молекулы перовскита от их взаимодействия с окружающей средой (воздухом, парами воды и пр.) (см., например, [8]). Необходимо добавить, что, несмотря на то что измерения проводились на образцах композитов $\mathrm{CH}_{3} \mathrm{NH}_{3} \mathrm{PbI}_{3}$ : $\mathrm{CE}$, находящихся на открытом воздухе, не было замечено деградации THz-характеристик приготовленных пленок композитов. Результаты THz-измерений, проведенных на свежеприготовленных образцах, воспроизводились после выдерживания образцов на воздухе в течение нескольких недель. Полученные композитные пленки $\mathrm{CH}_{3} \mathrm{NH}_{3} \mathrm{PbI}_{3}$ : $\mathrm{CE}$ перспективны при разработке новых эффективных композитных солнечных элементов, светодиодов и полевых транзисторов с повышенной стабильностью характеристик.

Таким образом, методом THz-спектроскопии во временно́й области исследованы композиты металлоорганический перовскит $\mathrm{CH}_{3} \mathrm{NH}_{3} \mathrm{PbI}_{3}-$ смешанный эфир целлюлозы в диапазоне частот $0.2-2.9 \mathrm{THz}$. Установлено, что добавка смешанного эфира целлюлозы в композит, способствующая предотвращению быстрой деградации
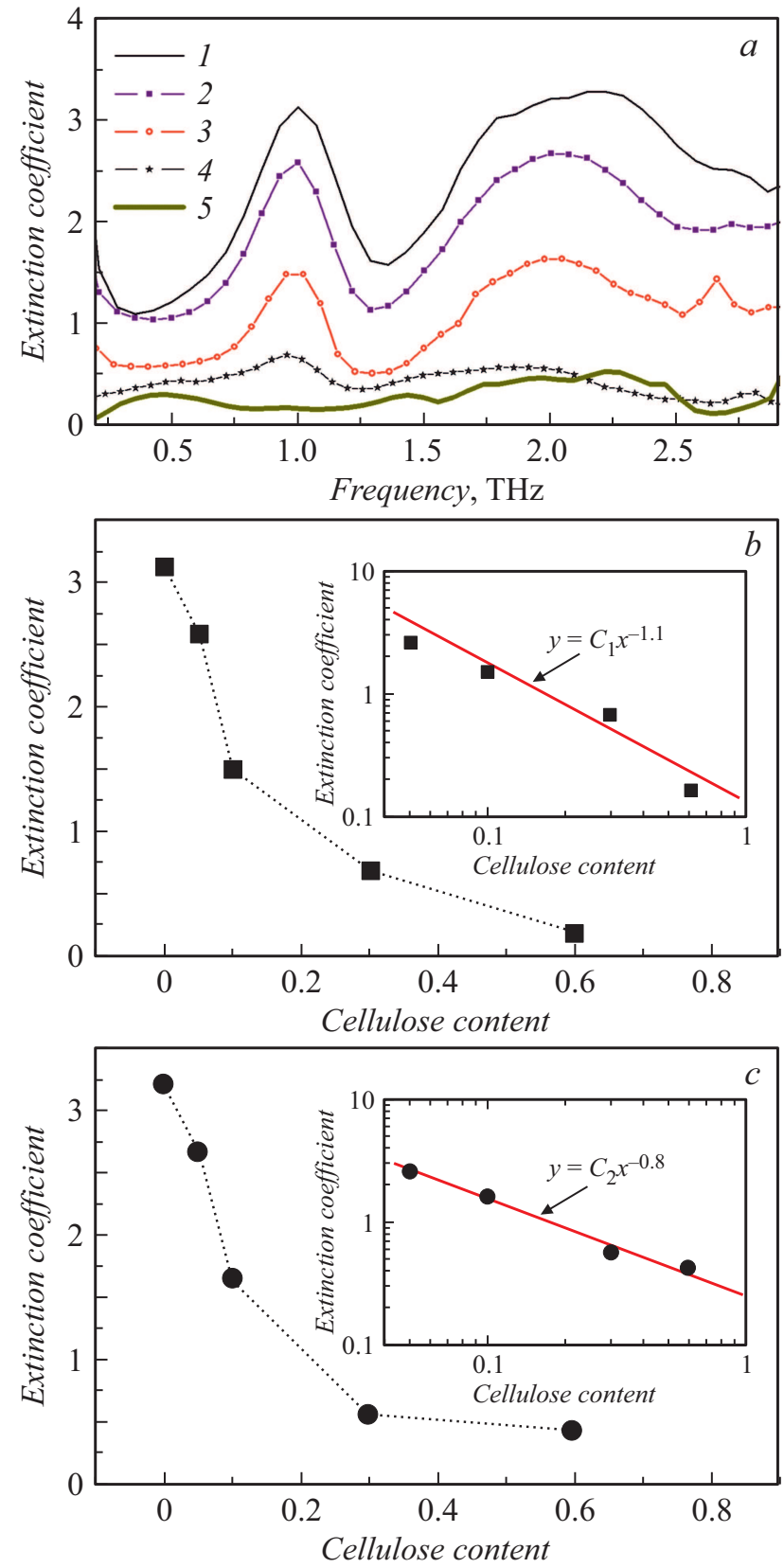

Pис. 3. $a-$ спектры коэффициента экстинкции композита $\mathrm{CH}_{3} \mathrm{NH}_{3} \mathrm{PbI}_{3}$ : $\mathrm{CE}$ с различным соотношением компонентов $\mathrm{CH}_{3} \mathrm{NH}_{3} \mathrm{PbI}_{3}$ и $\mathrm{CE}: 1-100 \%$ перовскит, $2-0.95: 0.05$, $3-0.9: 0.1,4-0.7: 0.3,5-0.4: 0.6 ; b$ и $c-$ зависимости коэффициента экстинкции на частотах $1(b)$ и $2 \mathrm{THz}(c)$ для композита $\mathrm{CH}_{3} \mathrm{NH}_{3} \mathrm{PbI}_{3}$ : $\mathrm{CE}$ от содержания целлюлозы в композите. На вставке представлены результаты аппроксимации экспериментальных данных степенной функцией.

перовскита и повышению стабильности его фотоэлектрических свойств в области межзонного поглощения, в то же время приводит к значительному ослаблению полос THz-поглощения в области частот порядка 1 и $2 \mathrm{THz}$, обусловленных возбуждением низкочастотных колебательных мод в молекулах перовскита $\mathrm{CH}_{3} \mathrm{NH}_{3} \mathrm{PbI}_{3}$. Данная закономерность может быть объ- 
яснена тем, что молекулы эфира целлюлозы, обволакивая молекулы перовскита, демпфируют низкочастотные колебания в них.

\section{Благодарности}

Авторы выражают благодарность А.К. Хрипунову за предоставление смешанного эфира целлюлозы с ацетотриметилацетатом.

\section{Конфликт интересов}

Авторы заявляют, что у них нет конфликта интересов.

\section{Список литературы}

[1] Ono L.K., Qi Y. // J. Phys. D: Appl. Phys. 2018. V. 51. P. 093001

[2] NREL efficiency chart [Электронный ресурс]. Режим доступа: http://www.nrel.gov/ncpv/images/efficiency_chart.jpg (дата обращения: январь 2020).

[3] Wehrenfennig C., Eperon C.E., Johnston M.B., Snaith H.J., Herz L.M. // Adv. Mater. 2014. V. 26. P. 1584-1589.

[4] Wehrenfennig C., Liu M., Snaith H.J., Johnston M.B., Herz L.M. // Energy Environ. Sci. 2014. V. 7. P. 2269-2275.

[5] La-o-vorakit $C$., Salim T., Kadro J., Khuc M.-T., Haselsberger R., Cheng L., Xia H., Gurzadyan G.G., Su H., Lam Y.M., Markus R.A., Michel-Beyerle M.-E., Chia E.E.M. // Nature Commun. 2015. V. 6. P. 7903.

[6] Manshor N.A., Wali Q., Wong K.K., Muzakir S.K., Fakharuddin A., Schmidt-Mende L., Jose R. // Phys. Chem. Chem. Phys. 2016. V. 18. P. 21629-21639.

[7] He J., Ng C.-F., Wong K.Y., Liu W., Chen T. // ChemPlusChem. 2016. V. 81. P. 1292-1298.

[8] Aleshin A.N., Shirinkin P.P., Khripunov A.K., Shcherbakov I.P., Trapeznikova I.N., Petrov V.N. // Cellulose. 2020. In press.

[9] Tsvetkov N.V., Bushin S.V., Bezrukova M.A., Astapenko E.P., Mikusheva N.G., Lebedeva E.V., Podseval'nikova A.N., Khripunov A.K. // Cellulose. 2013. V. 20. P. 1057-1071.

[10] Andrianov A.V., Aleshin A.N., Truhin V.N., Bobylev A.V. // J. Phys. D: Appl. Phys. 2011. V. 44. P. 265101 (1-6).

[11] La-o-vorakit C., Xia H., Kadro J., Salim T., Zhao D., Ahmed T., Lam Y.M., Zhu J.-X., Marcus R.A., MichelBeyerle M.-E., Chia E.E.M. // J. Phys. Chem. Lett. 2016. V. 7. P. $1-6$.

[12] Андрианов А.В., Алешин А.Н., Матюшкин Л.Б. // Письма в ЖЭТФ. 2019. Т. 109. В. 1. С. 30-35. 